\title{
Numerical Simulation Analysis on Shear Bond Behavior of PUFA-to-Concrete Interface
}

\author{
Qifeng $\mathrm{Xu}^{*}$ and Lianzhen Zhang \\ School of transportation of science and engineering, Harbin Institute of technology, Harbin city, China \\ ${ }^{*}$ Corresponding author
}

\begin{abstract}
The paper mainly focus on the new type of reinforcement with polyurethane-fly-ash(PUFA) reinforced concrete interface problem. ABAQUS is used to study the debonding behavior of PUFA-concrete with in-plane shear test method. Plastic damage model is used for concrete materials. Flow Angle, dilatation angle and elastic modulus of concrete model are calibrated through the the test. The interface layer is simulated by the transition elements and interface layer material parameters are set up reasonably. The damage process of the interface layer is simulated and analyzed, and the strain distribution curve and the load slip curve of the interface layer are given by the displacement loading mode. The results of numerical simulation results are compared with the experiment and the results verify the reliability of numerical simulation.
\end{abstract}

Keywords-concrete; PUFA; interfacial mechanical behavior; debonding plastic-damage model

\section{INTRODUCTION}

PUFA(polyurethane-fly-ash) is isotropic homogeneous composite materials formed with additives and normal temperature and pressure, which taking polymer generated by modified cyanamide and polyester polyol as the matrix, taking the industrial fly ash as the reinforced materials. PUFA is widely used in bridge engineering reinforcement because of its high strength, light weight and the characteristics of toughness. However, a large number of specimens often have interface damage in the reinforcement process. Therefore, one of the key problems to reinforcment is the mechanical properties of the interface between the reinforcing material and the original structure.

Many scholars have carried out extensive researches on the mechanical properties of reinforced concrete interface[1-7]and a large amount of experimental data and abundant research results are presented. However, there are still some limitations in these studies. In this paper, ABAQUS is used to simulate the shear debonding test of PUFA-concrete interface and the results are compared with the experimental results, which verifies the correctness of numerical simulation analysis.

\section{EXPERIMENTAL DETAILS}

The In-plane shear test method is used in the test. The test need to consider the factors including the thickness $(10 \mathrm{~mm}$, $15 \mathrm{~mm}, 20 \mathrm{~mm})$, length $(70 \mathrm{~mm}, 110 \mathrm{~mm}, 130 \mathrm{~mm}, 150 \mathrm{~mm}$, $170 \mathrm{~mm})$, width of PUFA(25mm, 50mm, $75 \mathrm{~mm})$ and the strength of concrete (25.8MPa, 30.2MPa, 47.6MPa).A total of 25 in-plane shear specimens are designed by orthogonal experimental design method. The in-plane shear specimens are stripped and damaged by tension at both ends. Strain gauges are placed every $1.5 \mathrm{~cm}$ along the direction of PUFA bonding with concrete, as shown in the Figure.1.

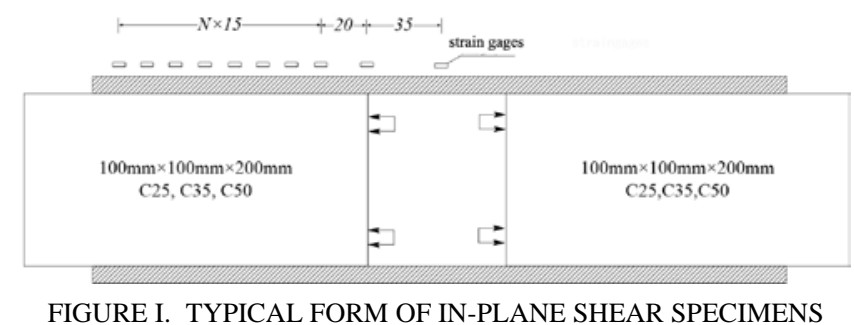

\section{FINITE ELEMENT ANALYSIS}

\section{A. Model establishment}

Due to the transition layer formed by chemical reaction at the interface of PUFA- concrete, debonding failure may occur in the concrete layer, but it may also occur in the PUFA layer. According to the data obtained from the interface mechanics test, the corresponding parameters of concrete constitutive model are verified, and then the whole bond-slip process is simulated by the transition layer element. In this paper, unit size model of $1 \mathrm{~mm}$ and large size model are established. The $1 / 4$ model is adopted. The unit type is C3D8R and the unit size is $5 \mathrm{~mm}$. The finite element mesh is shown in Figure.2.

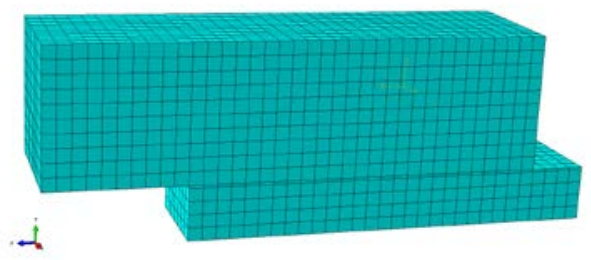

FIGURE II. MESH GENERATION

\section{B. Materials}

The concrete is simulated by the plastic damage model CDP in the ABAQUS. In Table 1, the dilatation angle, flow deflection angle and elastic modulus of three kinds of concrete are given. 
TABLE I. CONCRETE MATERIAL PARAMETERS (PLASTIC DAMAGE MODEL)

\begin{tabular}{|c|c|c|c|c|c|}
\hline $\begin{array}{c}\text { fcm(M } \\
\mathbf{P a})\end{array}$ & $\begin{array}{c}\text { Elastic } \\
\text { modulus } \\
(\mathbf{G P a})\end{array}$ & $\begin{array}{c}\text { Dilatation } \\
\text { angle }\left(^{\circ}\right)\end{array}$ & $\begin{array}{c}\text { Flow } \\
\text { deflection } \\
\text { angle }\end{array}$ & Kc & $\boldsymbol{V}$ \\
\hline 47.6 & 26.6 & 38.3 & 2.2 & 0.55 & 0.0006 \\
\hline 30.2 & 23.7 & 41.2 & 0.58 & 0.55 & 0.0006 \\
\hline 25.8 & 22.8 & 35.8 & 0.97 & 0.55 & 0.0006 \\
\hline
\end{tabular}

According to the test results, debond of PUFA interface layer occurred in some specimens in the in-plane shear test. Moreover, the strength of the interface layer is lower than that of PUFA itself. The properties of the interface materials are shown in Table 2.

TABLE II. MATERIAL PARAMETERS OF INTERFACE LAYER

\begin{tabular}{|c|c|c|c|c|}
\hline $\begin{array}{c}\text { Density } \boldsymbol{\gamma} \\
(\mathbf{g} / \mathbf{c m} 3)\end{array}$ & $\begin{array}{c}f_{c} \\
\mathbf{( M P a})\end{array}$ & $\begin{array}{c}f_{t} \\
\mathbf{( M P a})\end{array}$ & $\varepsilon_{0}$ & $\begin{array}{c}\mathbf{E} \\
\mathbf{( G P a )}\end{array}$ \\
\hline 0.45 & 7.44 & 2.60 & 0.0174 & 0.86 \\
\hline
\end{tabular}

\section{Experimental results}

After the unit is modeled, the model is calculated until the desired load displacement is reached. The Figure.3 is the condition of compressive and tensile damage factors during debonding failure of concrete. Damage factors, on the other hand, can reflect the units subjected to tension and compression failure. From the results, it can be observed that when the debonding failure occurs, concrete cracks occur basically, but the crushing is relatively lagging behind. The damage unit is located near the interface layer $5 \mathrm{~mm}$, which is consistent with the results of the tests. With the increase of load, there will be damage in the range of $5 \mathrm{~mm}$ to $10 \mathrm{~mm}$.

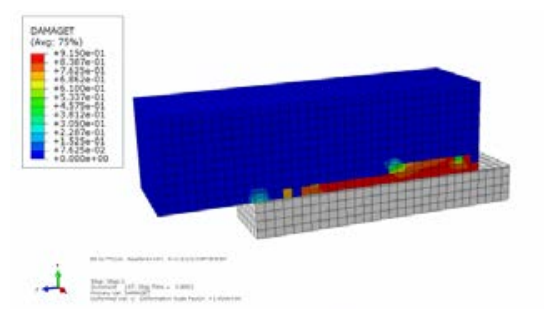

(A)

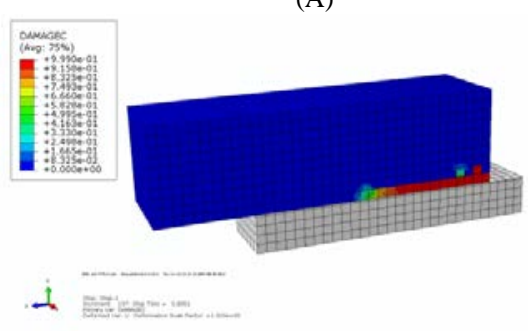

(B)

FIGURE III. DAMAGE FACTOR NEPHOGRAM:(A) NEPHOGRAM OF TENSILE DAMAGE FACTOR(B)NEPHOGRAM OF COMPRESSIVE DAMAGE FACTOR

The following Figure 4 is the plastic principal strain vector diagram of cohesive layer concrete. The plastic strain can reflect the plastic deformation of the unit. The maximum plastic principal strain refers to the tensile strain of concrete, which can explain the extent of tensile deformation or the size of crack. The minimum plastic principal strain refers to the compressive strain of concrete. The direction of the main compressive strain is perpendicular to the direction of the main tensile strain, which can be used to indicate the direction of the fracture .It can be seen from the diagram that the direction of the cracks at the bonding layer of concrete is 45 degrees of the concrete layer. Distress in concrete at the end are the largest. The crack develops along the direction of the force to the free end.

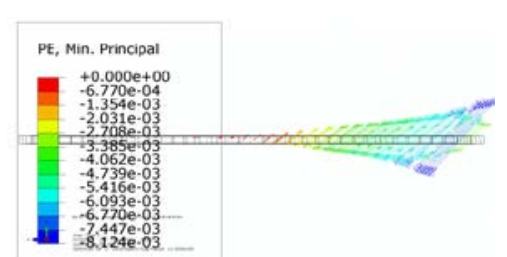

(A)

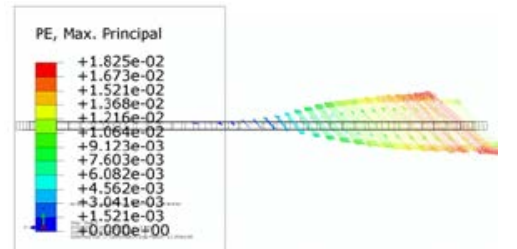

(B)

FIGURE IV. PLASTIC PRINCIPAL STRAIN VECTOR DIAGRAM OF INTERFACE LAYER (UNIT:MICRO STRAIN):(A)PLASTIC PRINCIPAL COMPRESSIVE STRAIN;(B)PLASTIC PRINCIPAL TENSILE STRAIN

The following Figure 5 is a comparison between the finite element results of the strain distribution along the PUFA bond path and the experimental results. Compared with the experimental results, the FEM results are more relaxed than the experimental ones, but the overall strain is consistent.

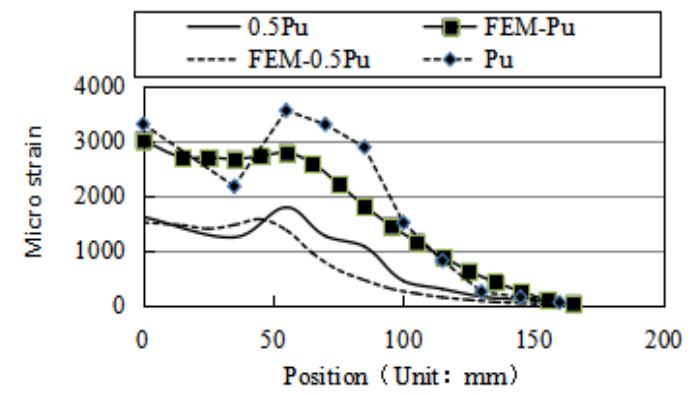

FIGURE V. COMPARISON BETWEEN EXPERIMENTAL STRAIN DISTRIBUTION AND DISTRIBUTION CALCULATED BY ABAQUS

The following Figure.6 is a comparison between the experimental load slip curves and the numerical simulation results. When the thickness of the transition layer is $1 \mathrm{~mm}$, that is to say, the debonding load of the former section agrees well with the test results, although there is an excursion in the peak displacement. It can be seen that ultimate debonding load of the specimen decreases, the tangent slope of the curve decreases and the shear stiffness decreases because of the existence of the transition layer. This indicates that the thickness of the transition layer will affect the value of the final debonding load, and will affect the bond slip constitutive relationship. The numerical simulation results show that the stiffness of the 
transition layer should be taken into account in the determination of the bond slip constitutive relationship.

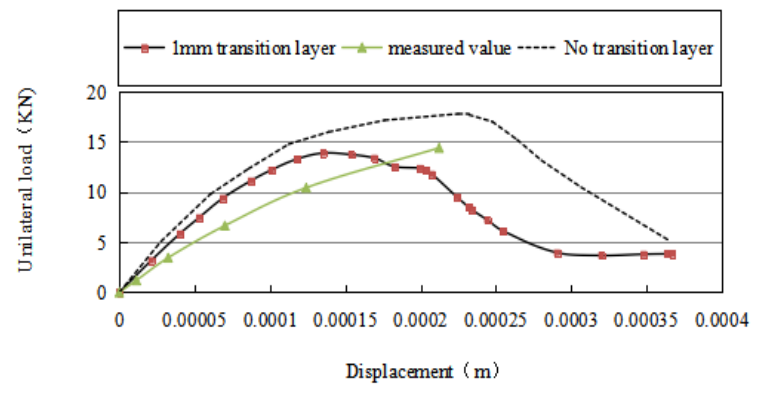

FIGURE VI. COMPARISON OF LOAD DISPLACEMENT CURVES WITH ABAQUS

Table 3 is the simulation results of the finite element model considering the transition layer and the comparison of the test results.

TABLE III. COMPARISON OF FINITE ELEMENT RESULTS WITH EXPERIMENTAL RESULTS

\begin{tabular}{|c|c|c|c|c|}
\hline $\begin{array}{c}\text { Specimen } \\
\text { number }\end{array}$ & $\begin{array}{c}\text { Test } \\
\text { value(KN) }\end{array}$ & $\begin{array}{c}\text { FEA none- } \\
\text { transition } \\
\text { layer (KN) }\end{array}$ & $\begin{array}{c}\text { FEA } \\
\text { transition } \\
\text { layer } \\
\text { (KN) }\end{array}$ & Pu/PFEA \\
\hline C25-10-25-70 & 10.5 & 11.2 & 8.1 & 0.77 \\
\hline C25-15-50-110 & 24.2 & 23.8 & 18.7 & 0.77 \\
\hline C25-20-75-130 & 35.5 & 33.9 & 28.2 & 0.81 \\
\hline C25-20-75-150 & 35.5 & 34 & 28 & 0.79 \\
\hline C25-20-75-170 & 35.5 & 35 & 28.4 & 0.8 \\
\hline C35-20-75-110 & 35.9 & 35 & 28.2 & 0.78 \\
\hline C35-20-75-130 & 36.9 & 36.9 & 27.4 & 0.74 \\
\hline C35-10-75-150 & 26.1 & 27.1 & 19.4 & 0.74 \\
\hline C35-15-25-170 & 14.9 & 15.3 & 11.3 & 0.76 \\
\hline C35-20-50-70 & 21 & 21.6 & 16.7 & 0.79 \\
\hline C50-15-75-130 & 35.7 & 36.2 & 28.3 & 0.79 \\
\hline C50-20-25-150 & 19.2 & 19.6 & 14.3 & 0.74 \\
\hline C50-20-50-170 & 32.5 & 33.2 & 24.5 & 0.75 \\
\hline C50-20-75-70 & 33.8 & 32 & 26.3 & 0.78 \\
\hline C50-10-75-110 & 29.2 & 28.6 & 23.1 & 0.79 \\
\hline C35-20-50-150 & 29.1 & 28.8 & 22.4 & 0.77 \\
\hline C35-10-75-170 & 26.1 & 26.5 & 20.4 & 0.78 \\
\hline C35-15-75-70 & 26.7 & 26.5 & 20.3 & 0.76 \\
\hline
\end{tabular}

From the above table, it can be seen that the debonding capacity decreases by about $20 \%$ because of the existence of PUFA transition layer. This should be considered when designing.

\section{RESUlts}

On the basis of 25 in-plane shear specimens, a large number of experimental studies and analyses are conducted on the bond behavior of PUFA materials to concrete. The ABAQUS plastic damage model is used to simulate the in-plane shear test, and the results are verified by experiments. The finite element analysis of the in-plane shear test of PUFA- concrete interface is carried out by the calibrated ABAQUS plastic damage model. The measured load slip curves are basically similar to those obtained by simulation. The measured ultimate load is basically consistent with the simulated results. The measured strain distribution is very close to the simulation results. At the same time, the damage process conforms to the measured interface failure process. The simulation results show that the reliability of the simulation method and provide a reference for further analysis.

\section{REFERENCES}

[1] De Lorenzis L, Miller B, Nanni A. Bond of FRP laminates to concrete[J]. ACI Materials Journal, 2001, 98 (3) : 256-264.

[2] Ueda T, Sato Y, Asano Y. Experimental study on bond strength of continuous carbon fiber sheet[J]. ACI Special Publication, 1999, 188.

[3] Takeo K, Matsushita H, Makizumi T, et al. Bond characteristics of CFRP sheets in the CFRP bonding technique[J]. Proc. of Japan concrete institute, 1997, 19 (2) : 1599-1604.

[4] de Sena Cruz J M, Oliveira de Barros J A. Bond between near-surface mounted carbon-fiber-reinforced polymer laminate strips and concrete[J] Journal of Composites for Construction, 2004, 8 (6) : 519-527.

[5] Wu Z, Yin J. Fracturing behaviors of FRP-strengthened concrete structures[J]. Engineering Fracture Mechanics, 2003, 70 (10) : 13391355.

[6] Smith S T, Teng J G. FRP-strengthened RC beams. I: review of debonding strength models[J]. Engineering Structures, 2002, 24 (4) : 385-395.

[7] Xinzheng, LU.Study on interface behavior of FRP-concrete[D].Peking: Tsinghua University, 2004. 